\title{
FINAL DE VERSO EN PARTÍCULA ÁTONA (TRADICIÓN E INNOVACIÓN MÉTRICA EN LA POESÍA DE ANTONIO CARVAJAL)
}

\section{José Enrique Martínez Fernández}

\author{
Universidad de León
}

«Una de las principales y más generales reglas para la buena elección de rimas y asonantes, y hasta ahora, que yo sepa, por ninguno advertida o notada, es que procure siempre el poeta preferir para consonante o asonante el sustantivo» (Luzán, 1977: 376). Es indudable que la rima así concebida subrayaría, además de palabras cargadas de significado, la unidad métrica y semántica del verso, apoyada — salvo en casos de encabalgamiento sirremático del tipo sustantivo / adjetivoen la pausa versal bien marcada; rima y pausa colaborarían en la percepción nítida del verso en cuanto tal, como unidad memorizable dentro de la estrofa. Esta preferencia de Luzán por la rima sustantiva frente a la adjetival se refleja en tratadistas posteriores, como Jovellanos y Munárriz, Bello o Gil de Zárate (vid. Domínguez Caparrós, 1975: 307, 318, 316 y 323). El caso de Benot es llamativo en este sentido, pues mide la importancia de la rima por su mayor o menor perceptibilidad, por lo que prescribe, entre otras cosas, que los versos terminen en sustantivos y 
verbos, palabras semánticamente llenas y, ordinariamente, de suficiente cuerpo fónico para ser delimitadas con claridad; en consecuencia, parece lógico que abogue por la pausa versal marcada y por la ausencia de un estilo muy cortado que perturbe la perceptibilidad de la rima (Domínguez Caparrós, 1975: 344). El adjetivo, aunque de cuerpo fónico suficiente, carecería de la independencia semántica del sustantivo o del verbo, por lo que era desechado como elemento de fin de verso entre nuestros tratadistas del XVIII y del XIX. De todo esto se deduce que los únicos encabalgamientos en que podían pensar eran del tipo sustantivo / adjetivo, algo extraño si tenemos en cuenta que ya Herrera (1580) había elogiado el encabalgamiento adjetivo / sustantivo en Garcilaso ( $Q$ Quién me dijera cuando en las pasadas / horas...») y que Cascales (1975: 119) alaba el encabalgamiento, sea de sustantivo / adjetivo o de adjetivo / sustantivo, apoyándose en el uso que hacen de él los grandes poetas italianos y españoles y en las ideas positivas de Bembo y de Minturno.

En cualquier caso, parece que al proponer la terminación en sustantivo, nuestros tratadistas pensaban en el verso como unidad de sentido, aunque haya que atribuir a Francisco Lorente el mérito de haberse dado cuenta de la necesidad de la pausa a final de verso y de su importancia (Domínguez Caparrós, 1975: 261), lo que le lleva, como a los demás tratadistas, a proponer terminar el verso en palabra semánticamente llena o a prever el verso como unidad de significado.

Parece indudable que se pensaba en el verso como objeto sonoro que, para su neta percepción, había que delimitar métrica y semánticamente por medio de la rima, la pausa y el sentido, dentro de una estrofa también delimitable. Desde este punto de vista, es lógica la proscripción de artículos, conjunciones y otros elementos fónica y semánticamente precarios del final de verso, los cuales perturbarían la clara percepción del mismo como tal unidad fonosemántica. Así lo vemos en Salvá o en Coll y Vehí (Domínguez Caparrós, 1975: 313 y 326-327). Tampoco Andrés Bello ve con buenos ojos el final de verso en monosílabos átonos, como el artículo definido o algunas preposiciones, añadiendo que es algo que sólo se hace en la poesía familiar y jocosa ( vid. Domínguez Caparrós, 1975: 314).

La terminación del verso en pronombre átono o preposición, conjunción o artículo en la poesía canónica afecta tanto a la rima como a la pausa. La función rítmica y demarcadora del verso que se les pedía tradicionalmente a la rima y a la pausa métrica versal queda desvaída con las partículas átonas a fin de verso; la percepción de éste como unidad fónica y semántica aparece desdibujada. Parece natural pensar 
que la rima, por serlo, deber ser perceptible; si tal perceptibilidad disminuye o se apaga, una de las funciones tradicionales de la rima queda también atenuada. Y el verso como unidad fónico-semántica puede empezar a diluirse, al menos acústicamente, porque sobre la página la percepción visual es incuestionable.

El final de verso en partícula átona nos introduce en el tema del encabalgamiento, fenómeno relacionado con la pausa versal. El encabalgamiento tiende a atenuar la percepción acústica de la pausa versal, justamente por lo que supone de desacuerdo entre dicha pausa rítmica y la pausa lógico-sintáctica. Entre los diferentes tipos de encabalgamiento, quizá el más contrario a los usos métricos españoles sea el de pronombre átono, preposición, conjunción o artículo / elemento que introducen. Que yo sepa, no se ha hecho un estudio diacrónico y estadístico del uso de cada uno de los encabalgamientos que diferenció en su estudio Quilis (1964). En lo que se refiere al que traemos entre manos, Quilis escribió en su día:

\begin{abstract}
No es muy corriente encontrar en nuestra poesía la escansión de un sirrema que esté construido por un elemento de relación, generalmente átono, y el término que introduzca. La marcada tonicidad que se siente en una palabra desprovista de valor analítico evita su colocación en posición final de verso encabalgante (1964: 99).
\end{abstract}

Aún así ponía algunos ejemplos de Villamediana (quando / Cerdofa), Francisco de la Torre (donde / queda muerto), Darío (y en / las montañas), Sor Juana Inés de la Cruz (se / revocará) y Calderón (le / pierden). Quilis (1964: 100-101) transcribía el siguiente comentario de Robles Dégano que me permito traer a cuento:

\begin{abstract}
Ahora bien, ¿habremos de decir que esas palabras no son átonas? ¿Deberemos admitir que el acento final no es esencial al ritmo del verso? Creo que no: y aunque sea ciertamente duro ir contra tantos, y algunos tan buenos poetas, mi opinión es que todos esos versos son malos y antirrítmicos. La lectura de tales versos siempre resulta mala: porque, o se acentúa el monosílabo átono, poniendo sobre él y el vocablo siguiente una cadencia que repugna al oído y al sentido de la frase, o se lee sin la cadencia, y entonces los versos se convierten en verdadera prosa. Véase cómo Iriarte (Tomás) se burla de esta fea versificación:
\end{abstract}

Muchos dicen que porque al

verso siguiente va con

las palabras de otro, don

Fulano pasa por mal

versista; pero aun con tal

error, cumple como buen 
poeta, pues poniendo en sus versos cabales las sílabas, deja a otro más hábil colocarlas bien.

Así pues, retomando ideas anteriores, diremos que nuestros metricistas de los siglos XVIII y XIX rechazaron en general la terminación de verso en partícula átona $\mathrm{y}$, por lo tanto, la extraña rima que tal partícula provocaría, así como el encabalgamiento consiguiente; tal hecho sólo se daba y admitía en la poesía jocosa, justamente como juego o como gracia; cuando no, provocaba burlas como la de Iriarte. Sin intentar aquí un análisis exhaustivo, me parece que no me confundo al afirmar que fueron los modernistas, tan innovadores en la métrica (vid. Domínguez Caparrós, 1999), los que eliminaron la burla de esta manera de versificar e instalaron como práctica las partículas átonas en fin de verso.

En una breve cala a nivel de antología (Gimferrer, 1969), encuentro, por un lado, casos de fin de verso en una partícula tónica de relación; así, en distintos poetas (Lugones, Herrera y Reissig, Villaespesa, Juan Ramón Jiménez) se reitera la rima una / luna, producto de un encabalgamiento sirremático ciertamente violento; he aquí el caso de Herrera y Reissig: «Tal la exangüe cabeza, trunca y viva, / de un mandarín decapitado, en una / macábrica ficción, rodó la luna / sobre el absurdo de la perspectiva...» (Gimferrer, 1969: 155). El encabalgamiento más violento es el originado por la presencia a fin de verso de términos átonos, de muy escaso cuerpo fónico y textual (las, por, $y$, $q u e$, etc.), que producen sorprendentes parejas de rima; así, en Juan Ramón Jiménez:

\author{
El oro de la tarde está de fondo, y las \\ lumbres le transparentan el perfil ignorante: \\ la barba de la carne le idiotiza hacia tras \\ lo que la barba en pelo le enmema hacia adelante
}

(Gimferrer, 1969: 212)

De Pérez de Ayala son los versos siguientes:

Sus brazos, marmórea guirnalda tibia y sensual, me asieron, y ardió en sus ojos de esmeralda una infinita luz. Cedí.

(Gimferrer, 1969: 207) 
FINAL DE VERSO EN PARTÍCULA ÁTONA (TRADICIÓN E INNOVACIÓN MÉTRICA EN...

Al poeta colombiano Luis Carlos López pertenecen estos versos:

Hombre de pelo en pecho, rubio como la estopa, rubrica con la punta de su machete. Y por la noche cuando toma la lugareña sopa de tallarines y ajos, se afloja el cinturón...

(Gimferrer, 1969: 228).

Me detendré algo más en los casos de Rubén Darío y de Leopoldo Lugones. El Rubén de «Lo fatal» hizo rimar terror-por, y la colocación de la preposición en final de verso y de estrofa relevó la enumeración e intensificó el dolor de vivir: «Y sufrir por la vida y por la sombra y por / lo que no conocemos y apenas sospechamos»; pero fue en la «Epístola a la señora de Leopoldo Lugones» (incluida en El canto errante, 1907) donde Darío mostró toda su osadía y su inventiva respecto al fenómeno métrico que venimos investigando. La «Epístola» discurre en un tono coloquial - no prosaico- y familiar, y combina el buen humor, propiciado por una relación amistosa, con ciertas angustias íntimas. Rubén pone en juego muchos de sus recursos: versos en francés, rimas de nombres propios (Rodenbach - Bach; Dupín Chopín) o de palabras extranjeras (surmenage - sauvage), etc. Por lo que respecta al asunto que tratamos, es decir, el encabalgamiento sirremático con una unidad átona en final de verso, más el elemento que introduce en el verso encabalgado, encontramos los siguientes casos:

...a pesar de Nabuco, embajador, y de

los delegados panamericanos que

hicieron lo posible por hacer cosas buenas...

...

...con las alondras y con Garcilaso y con

el sport. ¿Bravo! Sí. Bien. Muy bien. ¿Y La Nación?

...

Por eso los astutos, los listos, dicen que no conozco el valor del dinero. ¡Lo sé!

...

El temporal no deja que entren los vapores. Y un yacht de lujo busca refugio en Porto-Pí.

$\cdots$

Ah, señora, si fuere posible a algunos el dejar su babilonia, su Tiro, su Babel... 
Estas osadías ¿se deben al tono familiar que Bello reclamaba para tales casos? Sea lo que sea, lo cierto es que Rubén atenta contra dos de las reglas tradicionales, una que afecta a la rima y otra que afecta a la pausa; las partículas gramaticalmente átonas se aprovechan como rima con palabras tónicas: con-nación, que-sé, y-Porto-Pí, el-Babel; riman incluso dos monosílabos átonos: de-que. La precariedad fónica de tales partículas disminuye la perceptibilidad de la rima; pero, además, el encabalgamiento consiguiente aminora la percepción de la pausa métrica versal, con lo que se atenúa, asimismo, la percepción del verso como unidad sintáctico-semántica acústicamente delimitada. Quilis (1993: 86) ha señalado que «la pausa y la rima constituyen el marco métrico del verso», de forma que, si el encabalgamiento viene a anular la pausa versal, la rima permanece como hito delimitador del verso; pero en los ejemplos de Rubén, al desvanecimiento de la delimitación versal parecen colaborar tanto la anulación de la pausa por el encabalgamiento como el tipo de rima, si no enteramente imperceptible, de escasísima entidad fónica.

En el caso de Leopoldo Lugones, la crítica ha subrayado siempre que en la variedad de sus rimas reside, en buena parte, la sorpresa que el autor pretende. Borges (1982: 11) subrayó el juego:

Como Byron o Browning, Lugones exploró las posibilidades lúdicas de la rima. Recordemos algunas de sus diabluras: boj-reloj, apio-Esculapio, sarao-cacao, copos-Atropos, garbo-ruibarbo, oréganos-lléganos, insuflapantufla, pícara-jícara, hongos-oblongos, orla-por la, petróleo-mole o, náyade-haya de, pretéritas-in vino veritas, apoteosis-dosis.

Por su parte, Jesús Benítez repite los ejemplos borgianos y añade algunos más: «Podemos encontrar que riman partículas gramaticales infrecuentes (luna / como una, orla / por la, náyade / haya de, petróleo ( mole o)», y —eludiendo aquí la ejemplificación- términos latinos, palabras de otros idiomas, nombres propios y, con frecuencia, términos que se oponen semántica o estéticamente (Benítez, 1988: 78-79). Lunario sentimental (1909) se inicia con el poema titulado «A mis cretinos», nombre con el que el autor parece fustigar a sus lectores de cara a la estética sorprendente de sus versos, de manera que el humor que rezuma la composición no anula una cierta agresividad. Una de sus estrofas dice así:

\footnotetext{
Y la luna en enaguas,

Como propicia náyade

Me besará, cuando haya de

Abrevarme en sus aguas.
} 
La estrofa siguiente alude de forma festiva a la violencia del encabalgamiento en los versos anteriores:

\author{
¿Qué tal? ¿La hipermetría \\ Precedente os sulfura? \\ Os la doy limpia y pura. \\ Pulverizadla. Es mía...
}

Estamos, pues, en el tono lúdico que, al parecer, acompañaba al final de verso en monosílabos átonos y a la rima formada por más de un elemento léxico (náyade / haya de). ¿Y no hay juego o «diablura» en los otros casos?:

La luz que tu veste orla

Gime de verse encadenada por la

Gravitación de sus siete soles

...

A tu suave petróleo,

El bergantín veloz,

No se sabe si es mole o

Fantasma precoz

Rimas así, aparte de la extrañeza, provocan, en realidad, la creación de palabras ocasionales, al menos desde el punto de vista fónico: «háyade», «porla», «móleo»... ${ }^{1}$.

No son raras en la poesía actual ingeniosidades de este tipo, a diferencia de lo que constataba Quilis en 1964. Dejando a un lado ejemplos accidentales anteriores, me parece que es a partir de 1970, con los novísimos y afines, cuando el encabalgamiento de una unidad de relación en fin de verso con la palabra que sigue empieza a tener una presencia abundante en la poesía; me refiero aquí únicamente a la poesía rimada y ordinariamente regular silábicamente, en la cual dicho fenómeno puede ir unido a la formación de rimas con más de un elemento léxico $^{2}$. Los elementos de relación mencionados son unidades átonas

1 Lo prueba la errata que encontramos en la edición del Lunario sentimental debida a J. Benítez (Madrid: Cátedra, 1988: 103): «Y la luna en enaguas, / Como propicia háyade / Me besará cuando haya de / Abrevarme en sus aguas».

2 Tales encabalgamientos son, en la poesía en verso libre, una más de las libertades conquistadas, y no es difícil espigar ejemplos; véase una breve muestra tomada de un 
y dependientes, carentes de autonomía, que forman con la palabra que introducen una sola entidad fónica (Alarcos Llorach, 1994: 198, 214, etc), por lo que su ruptura es, probablemente, de mayor calidad que el resto de los encabalgamientos, puesto que a la violencia rítmica añaden la violencia de la ruptura fónica. Hablo de ruptura porque, sin perder lo que pueda haber de ingenio, este tipo de encabalgamiento, que no dudo en llamar violento, forma parte del conjunto de mecanismos de ruptura y fragmentación que ilustran la manera de ser de una parte de la poesía contemporánea (vid. Martínez Fernández, 1996). Para mí no cabe duda de que, más allá de las ingeniosidades modernistas, el brusco encabalgamiento sirremático al que vengo refiriéndome tiene en la poesía contemporánea la función primordial de desfigurar, desleír o desarticular desde dentro los metros tradicionales y canónicos, de los cuales queda, a pesar de todo, la huella rítmica o visual, según los casos. A ello uno, como he dicho, la creación ocasional de nuevas palabras, como consecuencia de una violencia más: el encabalgamiento rompe momentáneamente la entidad fónica formada por la unidad átona y la palabra que introducen («la / Gravitación»), y a través de la rima recompone una nueva entidad fónica con la palabra anterior ( $\ll \mathrm{La}$ luz que tu veste orla / Gime de verse encadenada por la / Gravitación...»). En las líneas que siguen nos acercaremos a estos fenómenos métricos desde la poesía de Antonio Carvajal y, más concretamente, desde el poemario Serenata y navaja $(1973)^{3}$. Se ha insistido demasiado en el Carvajal barroquizante, en el poeta de extraordinaria maestría técnica, de hábil manejo de todos los recursos retóricos y de indiscutible perfección formal. Es casi un tópico $-\mathrm{y}$ a él se ha referido el propio poeta en alguna composición - aludir a Antonio Carvajal como il miglior fabbro de la poesía contemporánea, sin que dejen de expresarse en el tópico algunas reticencias ${ }^{4}$, tal vez por no ver la tensión dramática

solo poemario, La lágrima de Ahab (1999), de José María Álvarez: «Es una dicha sin pasado. Sólo un instante / de exaltación, la / Vida / más allá de lo comprensible»; «Podrías huir. Sin duda. La / nueva Luz del mundo, Octavio, te / perdonaría»; «Y sobre tu regazo, abandonada, esa mano, $y$ / caído en ella, en libro querido...»; «...tus suspi$\operatorname{ros}_{3}$ por / beberte», etc.

3 Serenata y navaja fue incluido en Extravagante jerarquía (Poesía 1968-1981) (Madrid: Hiperión, 1983, 67-133), que es por donde cito.

${ }^{4}$ He aquí una cita ilustrativa: «Poeta muy culturalista, con fuerte tendencia barroquizante, representa en la línea renovadora de los años sesenta una actitud singular: el retorno a las formas de sabor clásico en lo que éstas tienen de complejo dispositivo retórico. Su poesía, así, posee un fuerte sabor arcaizante, a medias entre el homenaje y la antigua teoría de la imitación, abandonada en nuestras letras desde, por lo menos, Zorrilla. Algunos de sus artificios habían caído prácticamente en desuso, por ejemplo, la rima partida, y no recordamos en la posguerra ningún cultivador tan persistente. Otros muchos recursos formales emplea, con los que se podría reconstruir un manual 
o la intensidad significativa que anidan bajo la sabia construcción del poema. Raramente se alude, en cambio, al hecho de que en sus versos hay tanto de tradición como de ruptura. En el asunto que venimos desarrollando, se trata de una ruptura desde el interior de los metros clásicos, forzándolos, violentándolos desde dentro, por dos razones principales, a mi parecer: la primera tiene que ver con el conocimiento exhaustivo de todos los recursos métricos que históricamente han fructificado en la poesía española y que han originado distintas teorizaciones a lo largo del tiempo; tal conocimiento lleva al poeta, en diferentes ocasiones, a contradecir los preceptos teóricos con una práctica efectiva de aquello que tradicionalmente había sido vedado (por ejemplo, el fin de verso en partícula átona); la segunda razón alude al hecho de que el cultivo de diferentes formas métricas no obedece al mero capricho de un hábil versificador o a propuestas previas a la composición del poema concreto, sino a necesidades expresivas (Chicharro, 1999: 41).

El propio Carvajal se ha referido a la desarticulación de las formas clásicas en los versos de Serenata y navaja, que supone, simultánea y consecuentemente, una visión desarticulada del mundo: «Cualquier lector de mi poesía puede apreciar, con una simple mirada, la evidente quiebra de las formas, manifestación sensible de una subversión más honda: El acompasado fluir de los alejandrinos, los equilibrados endecasílabos, casi siempre unos y otros agrupados en sonetos [en Tigres en el jardín], se ven sustituidos en Serenata y navaja (1973) por una versificación generalmente abrupta, en que la melodía del verso y el fluir de los conceptos entran en colisión. La lira, la silva, otras estrofas polimétricas, delatan una nueva visión, alterada, deformada, del mundo» (Carvajal, 1994) 5 .

Comprobémoslo inicialmente en el excelente poema titulado «Otoño ante el sentido»:

\author{
Amo los días de \\ noviembre: vino nuevo y crisantemos. \\ Días para la fe \\ perdida, cuando hemos \\ de estar luchando por lo que queremos \\ y contra lo que no \\ queremos.
}

\footnotetext{
de figuras. No es sin embargo la de Carvajal una poesía tan sólo anclada en el pasado o mimética, pues, aparte la soltura en el manejo desusado de estos recursos, no carece de personalidad» (Sanz Villanueva, 1984: 452).

5 Tomo la cita de Chicharro (1999: 41-42).
} 


\author{
Desde aquí veo lejanas \\ sierras de gris o do \\ menor; graves besanas, \\ las cosechas tardías, las tempranas \\ siembras; árboles, pocos; \\ melancolía, mucha; pero alguna \\ ironía de locos \\ pájaros, vaga luna, \\ frutas maduras que caen, bien una \\ a una, o que recoge \\ el hortelano con extraños mimos \\ $y$ depone en el troje \\ o solas o en racimos. \\ Veo también lo pobres que vivimos, \\ este no ser más que \\ fracaso y voluntad de ser dichoso. \\ Ah, pero yo ¿qué sé? \\ El día es tan hermoso, \\ el aire tan gozoso, \\ y tengo, todavía, un no sé qué de fe.
}

En el poema alienta el gozo de los sentidos ante lo que perciben en la estación otoñal, sea en la naturaleza inculta o en el campo labrado, pespunteado todo ello con toques reflexivos en torno a la polaridad humana de «fracaso y voluntad», voluntad de dicha y de fe («Días para la fe / perdida...»), o con íntimas sensaciones («melancolía mucha»), para terminar oponiendo - dentro de la mencionada polaridad humana- un tono de optimismo a pensamientos negativos anteriores. En el verso final resuena el eco de San Juan de la Cruz, al igual que en los versos 8-9 parece evocarse el título de Rubén Darío «Sinfonía en gris mayor», poema de Prosas profanas (1896), fenómeno que muestra la sutil intertextualidad de la obra de un poeta que cuenta con un lector doctus capaz, desde su enciclopedia personal, de remitir el texto a la tradición literaria, asumida, pero reelaborada, al igual que ocurre con las formas métricas. En este campo el poeta adopta una estrofa clásica, la lira garcilasiana, pero tal estrofa queda, de alguna manera, desfigurada: visualmente, al no separar gráficamente las liras y, en el caso del verso 7, al escalonarlo en dos líneas; el poema aparece gráficamente como un todo, sin blancos de separación entre estrofas, a lo que hay que unir el encabalgamiento en serie a lo largo de la composición; la rima es, ordinariamente, marca de fin de verso y de fin de estrofa, pero el encabalgamiento en serie o encadenado - sin respetar siquiera la pausa estrófica o mayor-, así como la consonancia de monosílabos de poca entidad fónica (artículos, conjunciones) contribuye a desfigurar la forma y manera de la lira garcilasiana; la nueva configuración motiva - me parece - un ritmo de lectura diferente a la de la estrofa canónica, 
la cual queda así desvaída y, en buena parte, oscurecida. «Otoño ante el sentido» nos habla a las claras de la apuesta de Carvajal por el encabalgamiento continuado, frente a las reticencias de los preceptistas, que tradicionalmente habían pedido un uso moderado del mismo; Herrera (1580) veía en el encabalgamiento «uno de los caminos principales para alcanzar la alteza y hermosura del estilo», si bien «este rompimiento no ha de ser continuo, porque engendra fastidio la continua semejanza». En general, los preceptistas de los siglos XVIII y XIX se muestran contrarios al abuso del encabalgamiento. Así, para Alfredo Camus «es positiva la variedad que da al verso, mientras que es negativa la confusión que puede traer consigo un uso desordenado del encabalgamiento» (Domínguez Caparrós, 1975: 289); tales reticencias llegan a Navarro Tomás, que escribe: «Es sin duda eficaz el encabalgamiento moderado y oportuno. Sus excesos han suscitado parodias burlescas» (vid. Domínguez Caparrós, 1975: 284, n. 140). Antonio Carvajal contradice, en la práctica, tales reservas, a la vez que logra para el encabalgamiento una función nueva: la dislocación, desde dentro, de los metros tradicionales. El estrofismo clásico hacía de la composición poética una suma de estrofas perfectamente cerradas, lo que permitía memorizar unidades estróficas sueltas de una determinada composición. Con el verso libre la unidad de composición pasó enteramente al poema. El estrofismo clásico no desapareció; el poeta podrá optar por el versolibrismo o por el verso regular agrupado en estrofas; pero puede también violentar las estructuras estróficas tradicionales por distintos procedimientos, sean gráficos o métricos; uno de estos procedimientos es el encabalgamiento continuado o en serie, que rompe el sentido del ritmo consabido y esperado de los metros tradicionales en favor de nuevas opciones de lectura. En el caso de los versos regulares y rimados, como los transcritos de Antonio Carvajal, este tipo de encabalgamiento es de mayor calidad rupturista en los casos de versos que terminan en una unidad átona de relación (de, que, etc.); en tales casos, el encabalgamiento contribuye a diluir el efecto de la rima, algo que se ve aumentado con el menor cuerpo fónico del monosílabo átono, con lo que la marca de fin de verso, atenuada por el encabalgamiento, queda apenas subrayada por una rima débil. El mecanismo combinado de monosílabos átonos a fin de verso y encabalgamiento continuado contribuye a la desarticulación de la lira en su concepción tradicional. Añadamos, finalmente, que la estructura de la lira, en el poema que hemos transcrito, no se mantiene como tal hasta el término de la composición, sino que presenta alguna irregularidad: la última estrofa consta, no de cinco, sino de seis versos, el último de los cuales es un ale- 
jandrino; frente a la forma tradicional de la lira, aBabB, la última estrofa presenta esta estructura: aBabbA, donde $\mathrm{A}$ es un alejandrino.

El doble mecanismo rupturista analizado en «Otoño ante el sentido» (final de partícula átona y encabalgamiento en serie) puede extenderse a otras composiciones de Serenata y navaja. Me parece distinguir, sin embargo, diferentes grados en el mecanismo desarticulador. El primero y más sencillo es el ya indicado de final de verso rimado en unidad átona de relación (de, del, que, por, su, etc.) con el encabalgamiento consiguiente que genera; tales unidades riman con palabras de mayor entidad fónica y significativa (en «Otoño ante el sentido» la entidad fónica de la palabra $f e$, que rima con la preposición de, y de las palabras sé y fe, que riman con la conjunción que es también escasa; pero en otros poemas encontramos estas rimas: que-minué-bouquet; por-sopor-amor). Un grado de mayor calidad desarticulatoria se produce cuando riman entre sí dos unidades monosílabas átonas, como que-de; la marca final de verso, visualizada gráficamente, es casi imperceptible acústicamente:

\author{
...de abnegaciones, que \\ los ojos y sus lágrimas, los labios \\ y la memoria de \\ los besos, de tan sabios \\ no sabían. Tiene el agua resabios... \\ («Vista de Badajoz al atardecer», p. 76)
}

En un escalón de superior osadía desarticulatoria, el poeta rompe la palabra por medio de un encabalgamiento léxico, de forma que es la primera parte de la palabra dividida la que ejerce la rima. Tal fenómeno no llama la atención cuando se trata de palabras compuestas, pues ya fray Luis de León lo había practicado en su oda a la «Vida retirada» ( «Y mientras miserable- / mente se están los otros abrasando / con sed insaciable...») (Quilis, 1963), al igual que hará Carvajal:

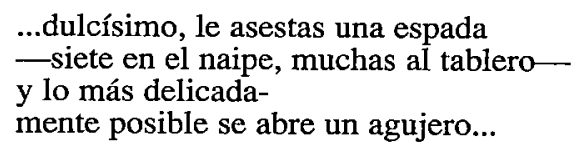

(«Siete de espadas», p. 101)

En los demás casos, se origina la ruptura de la palabra como unidad morfológica: 
...desolación! ¡Oh sobre-

cogedora armonía de la nube

cárdena contra el cobre

de las cúpulas! Sube

del corazón una fragancia - anduve...

(«Vista de Badajoz al atardecer», pp. 75-76)

...hasta el último extremo

de la injusticia...

Todo sea por ella

soportado, el endemo-

niado terror, la estrella

fugaz, la melodía dura y bella...

(«Una perdida estrella», p. 89)

$\mathrm{Si}$ «endemoniado» es palabra rota gráficamente, lo es también desde el punto de vista fónico, pues la palabrea dividida - pronunciada - en dos partes actúa como si se tratara de dos unidades fónicas diferentes, cada una con su acento (endémo-/niádo); la primera parte de la palabra, inicialmente átona y no propicia por ello para la rima, soporta ahora este principio rítmico. En un caso de extrema violencia, la ruptura de la palabra lleva aparejada la división de la sílaba (conde-/stable), aunque remita sabiamente a su composición original (comes stabuli):

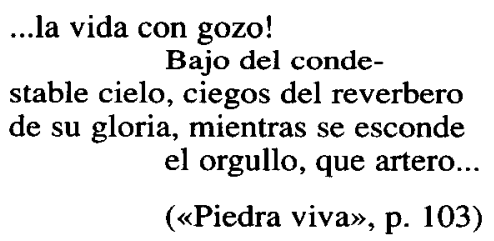

En el grado más alto de ruptura, la primera parte de la palabra dividida a fin de verso (encabalgamiento léxico) forma unidad rítmica con la palabra precedente:

...del trueno y el relámpago

del existir, vorágine de besos,

irresistible trampa, go-

zoso esplendor de ilesos

ángeles, que no humanos, inconfesos...

(«Vista de Badajoz al atardecer», p. 77) 
No eres tú, que la sueñas;

soy yo quien la contempla que la vive.

Ese cielo que enseñas,

música oscura si ve-

hemente pájaro que al cielo escribe...

(«Vista de Badajoz al atardecer», p. 75)

Fónica y rítmicamente lo que tenemos es la rima de sive con vive y escribe, y de relámpago con trámpago. Estas violencias morfológicas y fónicas son muestra de esa doble faz de tradición y renovación simultáneamente presentes en la poesía de Antonio Carvajal.

Otros casos semejantes hallamos en el poema «Mala hierba» (121122) (¿remite el título a la novela homónima barojiana?). Se trata de un poema en sextetos; Baehr denomina a dicha estrofa sexta rima o sextina real y dice de ella que es «como una octava real a la que hubiesen recortado los dos primeros versos» (Baehr, 1970: 276). En la primera estrofa riman con la-unión la- (mentable), y en la segunda vahoestá.jOh: «...un tibio trino, un cristalino vaho, / y su cuerpo presente en mi alma está. ¡Oh, // la carne apenas hecha todavía...». Como se ve, tales formas de rima originan forzadas recomposiciones fónicas: conla, uniónla (mentable); estáoh...

No he pretendido ser exhaustivo ${ }^{6}$. Conviene mirar hacia atrás y hacia adelante, si bien lo haré someramente, pues una investigación del asunto exigiría mayor detenimiento. Hacia atrás, en Casi una fantasía, publicado en $1975^{7}$, pero escrito en 1963 en sextetos, hallamos ya algunos juegos de rimas semejantes a los practicados posteriormente en Serenata y navaja; así riman corazón to- (talmente)-pronto o silencio-licencio-(samente). Hacia adelante, Carvajal no tenía ya que demostrar nada de su maestría técnica, reconocida y admirada; podía escribir liras, sonetos o verso libre; en todos los casos el dominio del verso es absoluto y no es raro oír hablar de la perfección formal de sus versos; podía también alardear de su ingenio. Y lo hizo, naturalmente. En lo que atañe a este trabajo me place detenerme en el poema titulado «Ad petendam pluviam», publicado inicialmente en 1993, en Poetas en el aula y recogido en 1996 en La Florida del Ángel. El

6 Si lo fuera, añadiría nuevos casos semejantes a los ya señalados y otros fenómenos curiosos, como la rima consonante simulada: pálida-impávida-sápida (p. 73); rayo-hallo-callo (p. 80), etc.

7 Casi una fantasía. Granada: Universidad, col. Silene; en Extravagante jerarquía (1968-1981), pp. 135-154. 
poema lleva el siguiente epígrafe: «(o de como conjurar una cursilada prosaria con unos cuantos versos de cabo doblado, un pseudo dáctilo cataléctico y otro quebrado)»:

¡Oh nube, cuánta calén-
dula en flor espera Llú-
via que le niegas tan hú-
raña y avara sabién-
do que es el gua sostén
de la flor y la alegrí-
a de cuerpos y alma ardí-
dos! ¡No celes sol, y col-
ma la sed con unos gol-
pes generosos y fluí-
dos de ti!

(Carvajal, 1996: 8)

Se trata de un curioso ejercicio literario, una décima «de artificio»o artificiosa a la que se añade un verso quebrado final. Como el poeta señala, la composición trata de «conjurar una cursilada prosaria»; en efecto, leído como prosa, es de una elegancia afectada y ridícula: ${ }_{i} \mathrm{Oh}$ nube, cuánta caléndula en flor espera Lluvia que le nieguas tan huraña y avara sabiendo que es el agua sostén de la flor y la alegría de cuerpos y alma ardidos! ¡No celes sol, y colma la sed con unos golpes generosos y fluidos de ti». La distribución en versos origina aquello que percibió Culler (1975: 229 y ss.) respecto a una noticia periodística transcrita como si de un poema lírico se tratara: los efectos sobre los lectores varían sustancialmente, entran en juego un conjunto de expectativas y de convenciones diferentes, de las que derivan nuevas interpretaciones... Pero el empeño de Carvajal tiene mucho de juego, emparentado, sin duda, con otros ejercicios de ingenio, como los versos de cabo roto, que originaron entre nuestros clásicos variantes burlescas de estrofas muy respetadas, como la décima o el soneto, por ejemplo. El poemilla de Carvajal se mantiene dentro de tal tono humorístico, pero utiliza lo que llama «cabo doblado», porque la palabra partida se dobla o cabalga sobre el verso siguiente, a diferencia del verso de cabo roto, en el que se suprimían las sílabas átonas de las palabras a fin de verso, originando la llamada «rima partida» - la misma que Carvajal practica entre las sílabas tónicas de tales palabras «dobladas»-.

Dejando a un lado, pero sin obliterarlo, este ejercicio artificioso, me parece que cabe concluir recordando lo que supone la terminación de los versos en palabras rotas, en preposiciones, conjunciones, artículos 
y pronombres personales átonos, con los consiguientes encabalgamientos en serie y la desfiguración de la pausa versal debida también a la atenuación de la función demarcadora de la rima (por la escasa entidad fónica de las partículas mencionadas): por una parte, puede hablarse de determinadas libertades adquiridas por la poesía contemporánea; por otra, se trata de factores que hay que relacionar con otros que han tendido a relajar las marcas auditivas de la poesía tradicional en favor de nuevas opciones de lectura.

\section{Referencias bibliográficas}

Alarcos Llorach, E. (1994). Gramática de la lengua española. Madrid: Espasa Calpe.

Álvarez, J. M. ${ }^{a}$ (1999). La lágrima de Ahab. Madrid: Visor.

BAEHR, R. (1970). Manual de versificación española. Madrid: Gredos.

BENITEZ, J. (1988). «Introducción» a Lugones, L. Lunario sentimental. Madrid: Cátedra, 11-87.

BoRGES, J. L. (1982). «Introducción» a Leopoldo Lugones. Antología poética. Madrid: Alianza, 7-13.

Carvajal, A. (1983). Extravagante jerarquía (Poesía 1968-1981). Madrid: Hiperión.

- (1993) Poetas en el aula (M. ${ }^{a}$ V. Atencia y A. Carvajal). Sevilla: Consejería de Educación y Cultura.

- (1994). «Noticia de los poemas». En Ciudades de provincia. Jaén: Diputación Provincial, 7-11.

- (1996). La Florida del Ángel. Montilla: Aula Poética Inca Garcilaso.

Cascales, F. (1975). Tablas poéticas. Ed. de B. Brancaforte. Madrid: Espasa Calpe (ed. original, 1616).

ChICHARRo, A. (1999). «Estudio previo» a A. Carvajal. Una perdida estrella. Madrid: Hiperión, 7-70.

CULLER, J. (1975). La poética estructuralista. Barcelona: Anagrama, 1978.

Domínguez CAPARrós, J. (1975). Contribución a la historia de las teorías métricas en los siglos XVIII y XIX. Madrid: CSIC.

- (1999). «El modernismo en la formación del verso español contemporáneo». En Estudios de métrica. Madrid: UNED, 181-207.

GimfERrer, P. (1969). Antología de la poesía modernista. Barcelona: Barral Editores.

HeRRera, F. de (1580). Obras de Garcilaso de la Vega con Anotaciones de..., en Gallego Morell, A. (Ed.), 1972. Garcilaso de la Vega y sus comentaristas. Madrid: Gredos, 305-594.

Lugones, L. (1909). Lunario sentimental. Ed. de J. Benítez. Madrid: Cátedra. 
FiNAL DE VERSO EN PARTíCULA ÁTONA (TRADICIÓN E INNOVACIÓN MÉTRICA EN...

LUZÁN, I. DE (1977). La poética o Reglas de la poesía en general, y de sus principales especies. Ed. de R. P. Sebold. Barcelona: Labor (1. ${ }^{a}$ ed., 1737).

MARTÍNEZ FERNÁNDEZ, J. E. (1996). El fragmentarismo poético contemporáneo. Fundamentos teórico-críticos. León: Universidad.

- (1999). «Sobre el encabalgamiento». Tropelías 7-8, 193-215.

QuiLIS, A. (1963). «Los encabalgamientos en -mente de fray Luis de León y sus comentaristas». Hispanic Review 31, 22-39.

- (1964). Estructura del encabalgamiento en la métrica española. Madrid: CSIC.

- (1993). Métrica española. Barcelona: Ariel (7. $\left.{ }^{\mathrm{a}} \mathrm{ed}.\right)$.

SANZ Villanueva, S. (1984). Historia de la literatura española. 6/2. Literatura actual. Barcelona. Ariel. 